\title{
ESTRATÉGIAS DE MANEJO DA PALHA DE AZEVÉM PARA CULTIVO DO ARROZ IRRIGADO EM SUCESSÃ ${ }^{(1)}$
}

\author{
Silmara da Luz Correia ${ }^{(2)}$, Paulo Regis Ferreira da Silva ${ }^{(3)}$, Michael da Silva Serpa ${ }^{(2)}$, \\ Vladirene Macedo Vieira ${ }^{(2)}$, Madalena Boeni ${ }^{(4)}$ \& Guilherme Borba Menezes ${ }^{(5)}$
}

\begin{abstract}
RESUMO
A adoção de sistemas de rotação e sucessão de culturas é um dos pré-requisitos fundamentais para sustentabilidade dos sistemas de produção agrícola. Diante disso, o objetivo deste trabalho foi avaliar os efeitos de época de dessecação do azevém e de dose de adubação nitrogenada, aplicada na semeadura do arroz irrigado em sucessão, como estratégias para viabilizar o uso dessa sucessão em áreas de cultivo de arroz irrigado. $O$ experimento foi conduzido no campo em dois anos agrícolas (2008/09 e 2009/10), em Cachoeirinha, RS, em um Gleissolo Háplico Ta distrófico típico. Utilizou-se o delineamento de blocos casualizados, em parcelas subdivididas, com três repetições. Os tratamentos foram constituídos de quatro épocas de dessecação do azevém (90, 70,50 e 30 dias antes da semeadura do arroz, no primeiro ano; e 49, 34, 19 e 6, no segundo ano), de cinco sistemas de manejo da adubação nitrogenada no arroz irrigado, obtidos pela combinação de quatro doses de $N$ na semeadura $\left(0,10,20\right.$ e $\left.40 \mathrm{~kg} \mathrm{ha}^{-1}\right)$ e de quatro doses de $\mathrm{N}$ em cobertura (150, 140,130 e $110 \mathrm{~kg} \mathrm{ha}^{-1}$ ), totalizando $150 \mathrm{~kg} \mathrm{ha}^{-1}$, e de uma testemunha sem aplicação de $\mathbf{N}$, durante todo o ciclo da cultura. A presença de palha de azevém com as plantas mantidas de pé não prejudica o estabelecimento inicial de plantas de arroz cultivado em sucessão. O rendimento de grãos de arroz irrigado cultivado em sucessão ao azevém não é influenciado pela época de dessecação de azevém e pela dose de $\mathbf{N}$ aplicada em semeadura.
\end{abstract}

Index terms: Oryza sativa, Lolium multiflorum Lam., práticas de manejo, época de dessecação, adubação nitrogenada na semeadura.

\footnotetext{
(1) Trabalho apresentado no VII Congresso Brasileiro de Arroz Irrigado, Balneário Camboriú, SC, 2011. Recebido para publicação em 26 de abril de 2012 e aprovado em 16 de janeiro de 2013.

(2) Mestrandos do Departamento de Plantas de Lavoura, FA/UFRGS. Bolsistas do CNPq. Av. Bento Gonçalves, 7712. CEP 91540000 Porto Alegre (RS). E-mail: silcorreia@gmail.com; micaserpa@yahoo.com.br; vladirene@gmail.com

(3) Professor Colaborador Convidado da FA/UFRGS, Pesquisador do CNPq e Consultor Técnico do Instituto Rio Grandense do Arroz (IRGA), E-mail: paulo.silva@ufrgs.br

(4) Dra. em Ciência do Solo da Equipe de Agronomia, Estação Experimental do Arroz/IRGA. Av. Bonifácio Carvalho Bernardes, 1494. CEP 94930-030 Cachoeirinha (RS). E-mail: madaboeni@hotmail.com

(5) Graduando FA/UFRGS. Bolsista de Iniciação Científica PIBIC/CNPq/UFRGS. E-mail: menezes_fritz@yahoo.com.br
} 


\title{
SUMMARY: MANAGEMENT STRATEGIES OF RYEGRASS STRAW FOR RICE CROP GROWN IN SUCCESSION
}

\begin{abstract}
The adoption of crop rotation and crop sequence systems is one of the fundamental prerequisites for the sustainability of agricultural production. Therefore, the objective of this study was to evaluate the effects of ryegrass desiccation time and nitrogen fertilizer applied at sowing of irrigated rice, in succession, as a management strategy in irrigated rice cultivation. The field experiment was carried out in two growing seasons (2008/09 and 2009/10), in Cachoeirinha, State of Rio Grande do Sul, Brazil, on a typical dystrophic Ta Haplic Gleysol. The design was a randomized complete block, with three replications. The treatments, laid out in split plots, consisted of four periods of ryegrass desiccation (90, 70, 50 and 30 days before sowing rice in the first year, and 49,34, 19 and 6 in the second year of cultivation), and five nitrogen fertilization systems of rice, consisting of a combination of four $N$ rates applied at sowing $\left(0,10,20\right.$, and $\left.40 \mathrm{~kg} \mathrm{ha}^{-1}\right)$ and four $N$ rates as top dressing $(150,140,130$, and $110 \mathrm{~kg}$ $\left.\mathrm{ha}^{-1}\right)$, resulting in a total of $150 \mathrm{~kg} \mathrm{ha}^{-1}$, plus a control without $N$ application throughout the crop cycle. The initial establishment of rice plants grown in succession was not affected by the presence of upright-standing dry ryegrass plants. In both years, rice grain yield was not influenced by the desiccation time of ryegrass nor the $N$ rate applied at sowing.
\end{abstract}

Index terms: Oryza sativa, Lolium multiflorum Lam., management practices, desiccation time, nitrogen fertilization.

\section{INTRODUÇÃO}

No Estado do Rio Grande do Sul (RS), os denominados solos de terras baixas ocupam área de 5,4 milhões de hectares (ha), onde, anualmente, são cultivados cerca de 1 milhão de ha com arroz irrigado, cuja produtividade média de grãos na safra 2011/12 foi de 7,7 tha-1 (Menezes et al., 2012). O RS é o maior produtor de arroz irrigado do Brasil, contribuindo com quase $60 \%$ da produção nacional (CONAB, 2012).

Em algumas regiões arrozeiras do Estado, como a Depressão Central e as Planícies Costeiras Interna e Externa, o arroz irrigado é cultivado anualmente sem uso de plantas de cobertura de solo. Em outras, como a Fronteira Oeste, a Campanha e a Zona Sul, o arroz participa de sistemas com áreas em pousio, utilizadas com pecuária extensiva de corte, aproveitando-se a resteva do arroz e a pastagem nativa em intervalos de dois, três ou mais anos. Nessas regiões, há grande área em pousio, que vem sendo subutilizada. $\mathrm{O}$ cultivo contínuo de arroz irrigado pode reduzir a fertilidade do solo, quando não se realiza a reposição necessária de nutrientes; sem o cultivo do solo no período da entressafra com a produtividade de grãos, consequentemente, há aumento da incidência de pragas, doenças e plantas daninhas (SOSBAI, 2012).

A partir do início dos anos de 1990, surgiram sistemas alternativos para produção de arroz irrigado como a utilização do sistema de cultivo mínimo e, em menor escala, do plantio direto com uso de rotação e sucessão de culturas, com potencial para incrementar a produtividade em áreas de várzea (Vernetti Júnior et al., 2009a). Na safra 2011/12, a área cultivada nesses sistemas já representou $67,5 \%$ da área cultivada com arroz irrigado no RS (Menezes et al., 2012). O cultivo mínimo e o plantio direto na cultura do arroz irrigado diferenciam-se quanto à época de preparo do solo e ao tipo de cobertura vegetal. No sistema de cultivo mínimo, as operações de preparo do solo ocorrem geralmente no final do inverno até o início da primavera, de 60 a 45 dias antes da semeadura do arroz, sendo a cobertura vegetal composta principalmente por plantas daninhas. No plantio direto, o preparo do solo é realizado nos meses de janeiro a abril (preparo de verão), cultivando-se no inverno uma espécie de cobertura do solo e, ou, para pastejo dos animais, geralmente o azevém (Lolium multiflorum Lam.) (Embrapa, 2009). No entanto, a utilização do sistema plantio direto propriamente dito, ou seja, a adoção da prática de rotação e sucessão de culturas, em áreas de arroz irrigado, ainda é incipiente.

Entre os principais benefícios advindos do uso de sistemas de rotação e sucessão de culturas em áreas de arroz irrigado, destacam-se: reciclagem de nutrientes; redução dos níveis de infestação de plantas daninhas, principalmente de arroz vermelho; otimização do uso do solo e melhoria de sua qualidade pelo incremento de matéria orgânica; quebra de ciclos de doenças e pragas; otimização de uso de máquinas e mão de obra; diversificação de renda, aumento da produtividade e da rentabilidade do cultivo. Além disso, pode resultar em menor necessidade de aplicar fertilizantes, em razão do aproveitamento da adubação aplicada anteriormente, e implantar o próprio plantio direto (Vernetti Júnior et al., 2009a).

Entre as espécies possíveis de serem usadas como cobertura de solo no inverno e, ou, com o propósito de pastejo por animais no RS, destaca-se o azevém, pela sua ampla adaptação a esse ambiente (Menezes et al., 2001). Embora tenha muitas vantagens potenciais como cultura antecessora ao arroz, o manejo 
inadequado do azevém pode prejudicar o arroz irrigado em sucessão. A presença de alta quantidade de resíduos de azevém na superfície do solo, acima de 3,0 t ha $^{-1}$ de rendimento de massa seca, conforme classificação de Amado et al. (2000), pode dificultar a implantação e o desenvolvimento inicial das plantas de arroz em sucessão. A existência de resíduos em excesso, especialmente quando a dessecação é realizada muito próxima da semeadura do arroz, pode ser uma barreira física na operação de semeadura, por tornar difícil o corte da palha, o que pode deixar sementes de arroz descobertas, refletindo-se em redução da densidade inicial de plantas. Além disso, a presença de elevada quantidade de palha pode dificultar a perda de umidade do solo que, somada à condição de má drenagem, característica dos solos onde se cultiva arroz irrigado, pode resultar em atraso na semeadura do arroz. Com efeito, o atraso da época de semeadura para além de 10 de novembro é uma das causas determinantes para obter baixa produtividade na cultura do arroz (SOSBAI, 2012).

Outra possível limitação da presença de grande quantidade de resíduos de azevém, que geralmente apresenta alta relação $\mathrm{C} / \mathrm{N}$, relaciona-se ao maior consumo de nitrogênio $(\mathrm{N})$ pela biomassa microbiana do solo (BMS), imobilizando-o em sua massa celular, podendo causar deficiência desse nutriente no início do desenvolvimento das plantas do arroz em sucessão. Em resíduos culturais com valores de relação $\mathrm{C} / \mathrm{N}$ entre 25 e 30, há equilíbrio entre as intensidades dos processos de mineralização e imobilização (Allison, 1966).

Em cultivos de terras altas, vários trabalhos foram realizados para desenvolver estratégias de manejo de espécies de cobertura de solo no inverno, para cultivo de milho em sucessão (Silva et al., 2006, 2008), como usar sistemas de consórcio com espécies com baixa relação $\mathrm{C} / \mathrm{N}$, aumentar a dose de $\mathrm{N}$ mineral aplicado na semeadura do milho e elevar o intervalo de tempo entre a dessecação de espécies de cobertura de solo da família das poáceas e a semeadura desse cereal. Todas essas estratégias têm como objetivos principais elevar a taxa de decomposição de resíduos, diminuir o período de imobilização do N pela BMS (Victoria et al., 1992) e aumentar a disponibilidade de $\mathrm{N}$ à cultura em sucessão. Já nos ecossistemas onde é cultivado o arroz irrigado, são raros os estudos envolvendo sistemas de rotação e sucessão de culturas, em razão, principalmente, das limitações impostas pelas condições de solo hidromórfico, havendo poucas espécies adaptadas a essas condições (Menezes et al., 1994). Além disso, as condições anaeróbicas do solo, por causa da permanência de lâmina de água contínua durante a maior parte do ciclo de desenvolvimento da cultura, podem atuar de maneira diferenciada na decomposição de resíduos de espécies de inverno antecessoras ao arroz.

Neste contexto, o objetivo deste trabalho foi avaliar, durante dois anos agrícolas consecutivos, os efeitos de época de dessecação do azevém e de dose de adubação nitrogenada aplicada na semeadura do arroz irrigado em sucessão como estratégia para viabilizar o uso dessa sucessão e, consequentemente, contribuir para a sustentabilidade da atividade orizícola no Estado do Rio Grande do Sul.

\section{MATERIAL E MÉTODOS}

O experimento foi conduzido no campo da Estação Experimental do Arroz, do Instituto Rio Grandense do Arroz, em Cachoeirinha, RS, durante dois anos agrícolas (2008/09 e 2009/10), nas mesmas unidades experimentais. O solo da área experimental é classificado como Gleissolo Háplico Ta distrófico típico (Streck et al., 2008) e apresentou, em análise realizada em abril de 2008, os seguintes valores para os atributos físicos e químicos na camada de $0-20 \mathrm{~cm}$ : argila: $18 \%$ $(\mathrm{m} / \mathrm{v}) ; \mathrm{pH}\left(\mathrm{H}_{2} 0\right): 4,7$; índice SMP: 6,3; $\mathrm{P}$ (Mehlich-1): 39,2 $\mathrm{mg} \mathrm{dm}^{-3}$; $\mathrm{K}$ (Mehlich-1): $54 \mathrm{mg} \mathrm{dm}^{-3}$; matéria orgânica: $1,8 \%(\mathrm{~m} / \mathrm{v})$; Ca: $2,1 \mathrm{cmol}_{\mathrm{c}} \mathrm{dm}^{-3} ; \mathrm{Mg}: 2,1$ $\mathrm{cmol}_{\mathrm{c}} \mathrm{dm}^{-3}$ e CTC efetiva: $3,6 \mathrm{cmol}_{\mathrm{c}} \mathrm{dm}^{-3}$. A área experimental estava em pousio no verão há três anos antes da implantação do experimento. Nesse período, durante o inverno, havia o cultivo, em consórcio, das espécies serradela nativa (Ornithopus micranthus) e azevém (Lolium multiflorum Lam.), como cobertura de solo.

Inicialmente, os tratamentos planejados constavam de quatro épocas de dessecação do azevém $(45,30,15$ e 1 dias antes da semeadura do arroz) e de cinco sistemas de manejo da adubação nitrogenada no arroz irrigado, obtidos pela combinação de quatro doses de $\mathrm{N}$ na semeadura $\left(0,10,20\right.$ e $\left.40 \mathrm{~kg} \mathrm{ha}^{-1}\right)$, de quatro doses de N em cobertura $\left(150,140,130\right.$ e $\left.110 \mathrm{~kg} \mathrm{ha}^{-1}\right)$, totalizando $150 \mathrm{~kg} \mathrm{ha}^{-1}$, e de uma testemunha sem aplicação de $\mathrm{N}$ durante todo o ciclo do arroz (Quadro 1). O delineamento experimental foi de blocos casualizados, em parcelas

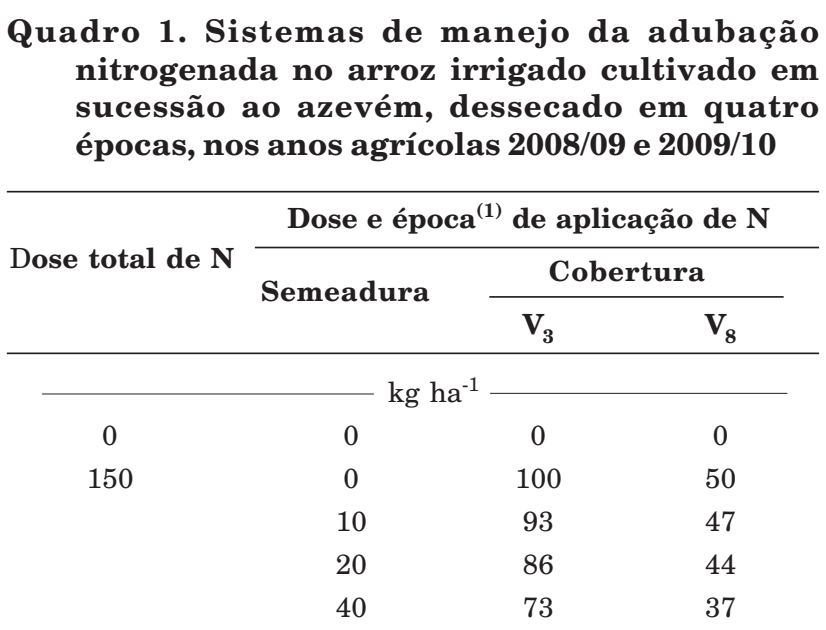

(1) De acordo com Counce et al. (2000). 
subdivididas, com três repetições. As épocas de dessecação do azevém foram locadas nas parcelas principais e os sistemas de manejo da adubação nitrogenada no arroz irrigado em sucessão, nas subparcelas.

No entanto, no primeiro ano, por causa da intensa precipitação pluvial ocorrida nos meses de setembro e outubro, houve atraso na época de semeadura do arroz. Dessa forma, as dessecações do azevém ocorreram aos 90, 70, 50 e 30 dias, antes da sua semeadura. Já no segundo ano, as dessecações foram aos 49, 34, 19 e 6 dias antes da semeadura do arroz; portanto, mais próximas das épocas inicialmente planejadas. Nos dois anos, não foi realizado nenhum tipo de manejo dos resíduos de azevém, com as plantas permanecendo de pé após a dessecação.

A semeadura do azevém foi realizada a lanço, na densidade de $25 \mathrm{~kg} \mathrm{ha}^{-1}$ de sementes, nos dias 15 de abril de 2008 e 12 de maio de 2009, sem aplicação de adubo NPK na semeadura. Em cobertura, foram aplicadas as doses de 100 e $45 \mathrm{~kg} \mathrm{ha}^{-1}$ de $\mathrm{N}$, respectivamente no primeiro e segundo anos, sendo $50 \%$ antes do início do perfilhamento e $50 \%$, aos 30 dias após. Utilizou-se ureia como fonte de fertilizante nitrogenado.

A semeadura do arroz, cv. IRGA 424, de ciclo médio, foi realizada em 13 de novembro de 2008 e, no segundo ano, em 19 de outubro de 2009; portanto, 25 dias mais cedo. Nos dois anos, realizou-se a semeadura no sistema plantio direto, na densidade de $100 \mathrm{~kg} \mathrm{ha}^{-1} \mathrm{de}$ sementes e com espaçamento entrelinhas de $0,17 \mathrm{~m}$. Logo após a semeadura, foi efetuada uma segunda dessecação de toda a área experimental. A adubação com P e K na semeadura do arroz foi feita para incrementar em 5,0 $\mathrm{tha}^{-1}$ a produtividade de grãos, em relação à produtividade média da área experimental, sem adição de adubo, que é de 5,5 t ha ${ }^{-1}$ (SOSBAI, 2012). No primeiro ano de semeadura do arroz, aplicaram-se $60 \mathrm{~kg} \mathrm{ha}^{-1} \mathrm{de}_{2} \mathrm{O}_{5}$ e $100 \mathrm{~kg} \mathrm{ha}^{-1} \mathrm{de} \mathrm{K}_{2} \mathrm{O}$ $\mathrm{e}$, no segundo ano, $50 \mathrm{~kg} \mathrm{ha}^{-1}$ de $\mathrm{P}_{2} \mathrm{O}_{5}$ e $110 \mathrm{~kg} \mathrm{ha}^{-1}$ $\mathrm{K}_{2} \mathrm{O}$, respectivamente na forma de superfosfato triplo e cloreto de potássio. As demais práticas culturais realizaram-se conforme as recomendações técnicas da pesquisa para o arroz irrigado no Sul do Brasil (SOSBAI, 2012).

Nos dois anos, a aplicação do adubo nitrogenado na semeadura do arroz foi realizada um dia após a semeadura, ao lado da linha, nas doses correspondentes aos tratamentos estabelecidos. A adubação em cobertura foi parcelada em duas épocas, conforme as recomendações técnicas para a cultura (SOSBAI, 2012), sendo dois terços da dose aplicados em solo seco no estádio $\mathrm{V}_{3}$, imediatamente antes da aplicação do herbicida e do início da irrigação, e o terço restante colocado sobre a lâmina de água no estádio $\mathrm{V}_{8}$, antes da iniciação da panícula.

$\mathrm{Na}$ cultura do azevém, avaliou-se no dia de sua dessecação, em cada época, o rendimento de matéria seca (MS) da parte aérea, pela coleta de plantas em uma área de $0,5 \mathrm{~m}^{2}$, secas em estufa a $60^{\circ} \mathrm{C}$ até atingir peso constante, sendo a quantidade de MS da amostra extrapolada para 1 ha.

No arroz irrigado, as determinações realizadas nos dois anos foram: densidade inicial de plantas, pela contagem de plantas no estádio $\mathrm{V}_{3}$ (antes do início do perfilhamento), em duas amostras de um metro de linha em cada subparcela, totalizando uma aérea de $0,34 \mathrm{~m}^{2}$; rendimento de matéria seca da parte aérea, avaliado no estádio $\mathrm{V}_{3}$, pela coleta de uma amostra de $0,17 \mathrm{~m}^{2}$ por subparcela, seca em estufa a $60^{\circ} \mathrm{C}$ até atingir peso constante, sendo a quantidade de MS da amostra extrapolada para um hectare; quantidade acumulada de $\mathrm{N}$ na parte aérea das plantas de arroz no estádio $\mathrm{V}_{8}$, pela coleta de uma amostra de $0,17 \mathrm{~m}^{2}$ por subparcela e determinado conforme descrito por Tedesco et al. (1995); componentes do rendimento: número de panículas por $\mathrm{m}^{2}$, obtido pela razão entre o número de panículas da amostra pela área demarcada, número de grãos por panícula, calculado pela razão entre o número total de grãos formados (extrapolado por regra de três a partir do peso de 200 grãos) e o número de panículas colhidas na área da amostra e o peso do grão, obtido pela pesagem de uma amostra de 200 grãos, contados manualmente, com correção da umidade para $13 \%$ e produtividade de grãos, estimada pela extrapolação da produção obtida na área útil da subparcela para 1 ha, corrigindo-se a umidade para $13 \%$. A área colhida para avaliação da produtividade foi de $16,8 \mathrm{~m}^{2}$, composta pelas 11 linhas centrais, com $9 \mathrm{~m}$ de comprimento.

Os dados meteorológicos relativos à radiação solar global dos dois anos avaliados foram obtidos junto ao $8^{\circ}$ DISME/INMET, em Porto Alegre, RS.

Os dados foram submetidos à análise de variância pelo teste $\mathrm{F}$. A comparação entre médias foi realizada pelo teste Duncan, a $5 \%$, utilizando-se o programa de processamento de dados SAS. Nos dois anos, para os dados de rendimento de MS da parte aérea de azevém, em razão da época de dessecação, realizou-se a análise de regressão.

\section{RESULTADOS E DISCUSSÃO}

A normal climática da radiação solar global aumentou de $13.324 \mathrm{~kJ} \mathrm{~m}^{-2}$ dia $^{-1}$, no primeiro decênio de setembro, até atingir o máximo de $22.039 \mathrm{~kJ} \mathrm{~m}^{-2}$ $\mathrm{dia}^{-1}$, no primeiro decêndio de janeiro (Figura 1). No primeiro ano (2008/09), durante a maior parte do ciclo do arroz irrigado, a radiação solar foi superior à normal climática, com exceção de dois períodos, o primeiro decêndio de janeiro e o terceiro decêndio de fevereiro até o segundo decêndio de março. Esses dois períodos corresponderam a estádios de desenvolvimento importantes para o arroz, $\mathrm{V}_{8}$ (época da segunda aplicação de ureia) e $R_{4}-R_{8}$ (florescimento - enchimento 


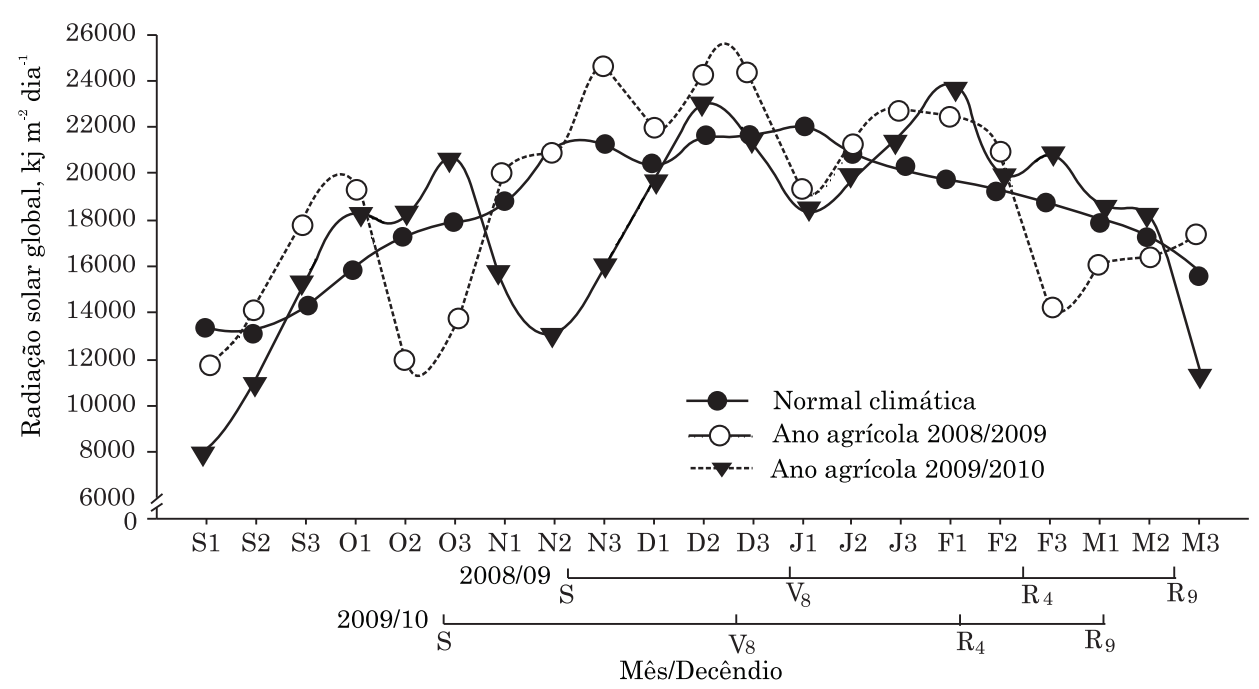

Figura 1. Radiação solar por decêndio nos meses de setembro a março, referente aos anos agrícolas 2008/09 e 2009/10 e à média do período de 1975 a 2002. Fonte: Cargnelutti Filho et al. (2004) e INMET (2012). Legenda: S: semeadura; $V_{8}$ : colar formado na oitava folha do colmo principal; $R_{4}$ : antese; e $R_{9}$ : maturidade completa dos grãos na panícula, conforme Counce et al. (2000).

de grãos), respectivamente. Do final do segundo decêndio de fevereiro até o segundo decêndio de março, a radiação solar foi, em média, $12 \%$ menor em relação à normal climática. Similarmente ao primeiro ano, no segundo ano, a radiação solar foi superior à normal climática durante a maior parte do ciclo do arroz, com exceção de dois períodos em que essa foi menor que a normal climática. $\mathrm{O}$ primeiro ocorreu do primeiro decêndio de novembro ao primeiro decêndio de dezembro, abrangendo os estádios $V_{1}$ e $V_{6}$ de desenvolvimento das plantas, e o segundo foi do terceiro decêndio de dezembro ao segundo decêndio de janeiro, compreendendo o período após a segunda aplicação de N no arroz. No segundo ano, a radiação solar foi, em média, $33 \%$ menor, em relação ao primeiro ano, durante o período da semeadura ao estádio $\mathrm{V}_{8}$; e $18 \%$ maior, em relação ao primeiro ano, durante o período de início da antese $\left(R_{4}\right)$ à maturação fisiológica $\left(\mathrm{R}_{9}\right)$.

$\mathrm{O}$ rendimento de MS de azevém no primeiro ano agrícola (2008/09) aumentou de forma quadrática com o atraso de época de dessecação, enquanto, no segundo ano, o aumento foi linear (Figura 2). Com dessecações realizadas mais próximas da semeadura do arroz irrigado, aumentou a duração do período de desenvolvimento da planta de cobertura, resultando em maior produção e acúmulo de fotoassimilados nas plantas. O rendimento de MS foi menor no segundo ano. Essa redução pode estar associada à maior adubação nitrogenada aplicada em cobertura no azevém no primeiro ano (100 $\left.\mathrm{kg} \mathrm{ha}^{-1} \mathrm{de} \mathrm{N}\right)$, em relação à adubação do segundo ano $\left(45 \mathrm{~kg} \mathrm{ha}^{-1} \mathrm{de} \mathrm{N}\right)$. Além disso, a presença de grande quantidade de palha de arroz dificultou o estabelecimento do azevém no segundo ano.
Nos dois anos, a densidade inicial de plantas de arroz irrigado não variou em razão da época de dessecação do azevém e das doses de $\mathrm{N}$ aplicadas na semeadura do arroz (Quadro 2). O estabelecimento inicial de plantas de arroz não foi influenciado, mesmo quando se obteve alto rendimento de MS do azevém, 7,2 $\mathrm{t} \mathrm{ha}^{-1}$ no primeiro ano, ou quando a época de dessecação foi mais próxima da semeadura, seis dias antes da semeadura no segundo ano, 3,9 $\mathrm{t} \mathrm{ha}^{-1}$. Portanto, a manutenção de alta quantidade de palha de azevém não constituiu-se em impedimento físico para a emergência de plantas de arroz em sucessão.

Independentemente do rendimento de matéria seca de azevém, a densidade de plantas de arroz variou nos dois anos de 221 a 262 plantas por $\mathrm{m}^{2}$, estando, portanto, de acordo com as recomendações da cultura, que é de 150 a 300 plantas por $\mathrm{m}^{2}$ (SOSBAI, 2012). Em estudos realizados no mesmo local por Vieira et al. (2011) e Marchesi et al. (2011), em que também foram obtidos altos rendimentos de MS de azevém, o estabelecimento inicial de plantas de arroz também não foi influenciado pela quantidade de MS de azevém produzida. No entanto, o fato da presença de resíduos de azevém não ter reduzido a densidade de plantas de arroz nesses dois anos de estudo contraria os resultados obtidos por Menezes et al. (2001), os quais observaram menor densidade de plantas de arroz em sucessão ao azevém, quando esse foi comparado a outras espécies de cobertura de solo (aveia preta, aveia branca e serradela nativa), à vegetação espontânea e testemunha pousio (solo desnudo). A redução da densidade de plantas de arroz em sucessão ao azevém foi atribuída a possíveis efeitos alelopáticos de resíduos de azevém sobre a germinação e a emergência de arroz em sucessão. 
O fato da densidade de plantas de arroz não ter variado em razão da época de dessecação do azevém, mesmo sob diferentes rendimentos de MS verificados nos dois anos, pode estar relacionado à manutenção da umidade do solo por maior intervalo de tempo durante o subperíodo semeadura-emergência do arroz, por causa da menor perda de água no solo com a presença da palha de azevém. Isso, também, pode limitar a penetração da radiação solar e reduzir a amplitude térmica no solo. Dessa forma, a camada de saturação de vapor de água ao solo é mantida, minimizando a perda de água (Salton, 1991).

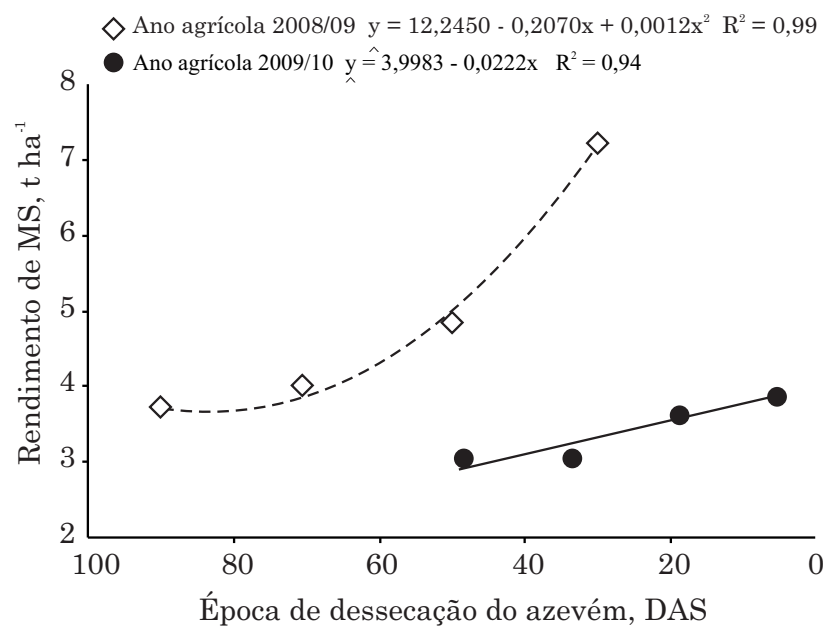

Figura 2. Rendimento de matéria seca (MS) da parte aérea de azevém em razão da época de dessecação, em dois anos agrícolas. DAS: dias antes da semeadura do arroz em sucessão.

Quadro 2. Densidade inicial de plantas de arroz irrigado em razão da época de dessecação de azevém, na média de doses de $\mathrm{N}$ aplicada na semeadura do arroz em sucessão

\begin{tabular}{|c|c|c|}
\hline Época de dessecação & Densidade inicial de plantas ${ }^{(2)}$ & $\mathbf{C V}^{(3)}$ \\
\hline $\mathbf{D A S}^{(\mathbf{1})}$ & plantas $/ \mathbf{m}^{2}$ & $\%$ \\
\hline & Ano agrícola 2008/09 & \\
\hline 90 & $221^{\mathrm{ns}}$ & \\
\hline 70 & 227 & \\
\hline 50 & 243 & 17,0 \\
\hline 30 & 259 & \\
\hline & Ano agrícola 2009/10 & \\
\hline 49 & 262 & \\
\hline 34 & 257 & \\
\hline 19 & 243 & 19,2 \\
\hline 6 & 248 & \\
\hline
\end{tabular}

${ }^{(1)}$ Dias antes da semeadura; ${ }^{(2)}$ Avaliação realizada com plantas no estádio $\mathrm{V}_{3}$, de acordo com Counce et al. (2000); ${ }^{(3)}$ Coeficiente de variação; $\mathrm{e}^{\mathrm{ns}}$ não significativo $(\mathrm{p}<0,05)$.
Nos dois anos, o rendimento de MS da parte aérea do arroz irrigado, avaliado antes da primeira época de aplicação do $\mathrm{N}$ em cobertura (estádio $\mathrm{V}_{3}$ ), não foi influenciado pela época de dessecação do azevém e pelas doses de $\mathrm{N}$ aplicado na semeadura (Quadro 3). A alta adubação utilizada na semeadura $(\mathrm{P} \mathrm{e} \mathrm{K})$ e o fato da área experimental estar há três anos em pousio antes da implantação do experimento, com cultivo em consórcio das espécies serradela nativa e azevém como cobertura de solo no inverno, podem ter contribuído para explicar a ausência de resposta à época de dessecação do azevém e às doses de $\mathrm{N}$ aplicado na semeadura do arroz.

No entanto, observou-se que, na média dos tratamentos, o rendimento de MS da parte aérea do arroz em $\mathrm{V}_{3}$ foi 56,2 \% menor no segundo ano em relação ao primeiro ano (Quadro 3), indicando que as condições meteorológicas no segundo ano foram mais desfavoráveis ao seu desenvolvimento inicial, conforme visualizado na figura 1 .

Já no estádio $\mathrm{V}_{8}$, a quantidade de $\mathrm{N}$ acumulada na parte aérea de plantas de arroz irrigado, que foi avaliada apenas no primeiro ano, não foi influenciada pela época de dessecação do azevém e pelas doses de $\mathrm{N}$ aplicado na semeadura (Quadro 3). A quantidade acumulada de $\mathrm{N}$ por hectare depende do seu teor no tecido e do rendimento de MS. Nesse estádio, verificouse pouca variação entre tratamentos, na quantidade acumulada do $\mathrm{N}$ e do rendimento de MS (dados não apresentados) da parte aérea da planta de arroz, e,

Quadro 3. Rendimento de matéria seca (MSPA) e quantidade de $\mathrm{N}$ acumulada por hectare na parte aérea (NPA) de plantas de arroz irrigado nos estádios $V_{3}$ e $V_{8}$ em razão da época de dessecação de azevém, na média de doses de $\mathrm{N}$ aplicada na semeadura do arroz em sucessão

\begin{tabular}{|c|c|c|}
\hline Época de dessecação & MSPA $^{(1)}$ & NPA $^{(2)}$ \\
\hline \multirow[t]{2}{*}{$\mathrm{DAS}^{(3)}$} & \multicolumn{2}{|c|}{$\mathrm{kg} \mathrm{ha}^{-1}$} \\
\hline & \multicolumn{2}{|c|}{ Ano agrícola 2008/09 } \\
\hline 90 & $50,6^{\mathrm{ns}}$ & $80,5^{\mathrm{ns}}$ \\
\hline 70 & 50,5 & 94,5 \\
\hline 50 & 56,7 & 82,3 \\
\hline 30 & 57,6 & 88,7 \\
\hline \multirow[t]{2}{*}{$\mathrm{CV}^{(4)}(\%)$} & 18,0 & 13,9 \\
\hline & \multicolumn{2}{|c|}{ Ano agrícola 2009/10 } \\
\hline 49 & 30,2 & $-(5)$ \\
\hline 34 & 33,8 & - \\
\hline 19 & 27,7 & - \\
\hline 6 & 29,4 & - \\
\hline $\mathrm{CV}(\%)$ & 29,3 & - \\
\hline
\end{tabular}

(1) Avaliação realizada com plantas nos estádios $V_{3}$ (três folhas expandidas) $\mathrm{e}^{(2)} \mathrm{V}_{8}$ (oito folhas expandidas), de acordo com Counce et al. (2000); ${ }^{(3)}$ Dias antes da semeadura. ${ }^{(4)}$ Coeficiente de variação. ${ }^{\text {ns }}$ não significativo $(\mathrm{p}<0,05) ;{ }^{(5)}$ Dados não mensurados no segundo ano. 
pelos mesmos motivos citados anteriormente, podem ter contribuído para a ausência de resposta à época de dessecação do azevém e às doses de $\mathrm{N}$ aplicado na semeadura do arroz.

$\mathrm{O}$ número de panículas por $\mathrm{m}^{2}$ foi o único componente do rendimento que foi influenciado pela época de dessecação e pelas doses de $\mathrm{N}$ aplicadas na semeadura do arroz, mas apenas no primeiro ano de estudo (Quadro 4), tendo diminuído com o atraso da época de dessecação. Os outros dois componentes, número de grãos/panícula e peso do grão, não foram influenciados pela época de dessecação do azevém e pelas doses de $\mathrm{N}$ aplicadas na semeadura do arroz; esses foram similares nos dois anos de estudo (dados não apresentados).

Embora no segundo ano não tenha havido diferenças significativas, observou-se tendência de redução desse parâmetro com o atraso da época de dessecação. Esses resultados demonstram que quanto mais próximo da semeadura for realizada a dessecação e quanto maior for o rendimento de MS do azevém, maiores podem ser os efeitos negativos de seus resíduos sobre esse componente do rendimento no arroz em sucessão. No entanto, a utilização de práticas culturais recomendadas, principalmente a época de semeadura mais adequada no segundo ano (19 de outubro de 2009), resultou em maior número de panículas por $\mathrm{m}^{2}$, próximo a 600 , que se considera como necessário para expressão do máximo potencial produtivo das cultivares de arroz irrigado (SOSBAI, 2010). Na média das épocas de dessecação, o número de panículas foi $60 \%$ maior no segundo ano, em relação ao primeiro, apesar de as condições de radiação solar terem sido mais desfavoráveis no início de desenvolvimento da planta no segundo ano.
O número de panículas por $\mathrm{m}^{2}$ foi, também, influenciado pela dose de $\mathrm{N}$ aplicada na semeadura do arroz. Observaram-se menores valores quando se aplicou a maior dose de $\mathrm{N}\left(40 \mathrm{~kg} \mathrm{ha}^{-1}\right)$ na semeadura, e na testemunha sem aplicação de $\mathrm{N}$ na semeadura. Esse componente do rendimento é o mais influenciado pela disponibilidade de nutrientes, principalmente de $\mathrm{N}$.

Nos dois anos, o rendimento de grãos de arroz não variou por causa da época de dessecação do azevém como cultura antecessora e de sistemas de manejo da adubação nitrogenada no arroz (Quadro 5). Com a aplicação da dose total de $150 \mathrm{~kg} \mathrm{ha}^{-1}$ de $\mathrm{N}$, na média de quatro sistemas de manejo da adubação nitrogenada, o rendimento de grãos foi 17,3 e 47,6 \% superior, em relação à testemunha, sem aplicação de $\mathrm{N}$ durante todo o ciclo do arroz, respectivamente no primeiro e segundo anos (Quadro 5). Esse decréscimo verificado no segundo ano evidenciou que o cultivo contínuo de arroz sem adubação nitrogenada não é sustentável, pois diminuiu o rendimento de grãos. Essa resposta diferencial entre anos com a aplicação de adubação nitrogenada pode estar relacionada, também, à menor disponibilidade de radiação solar durante o início do ciclo de desenvolvimento do arroz (semeadura ao estádio $\mathrm{V}_{8}$ ), verificada no segundo ano (Figura 1). A menor disponibilidade de radiação reduz a produção de fotoassimilados, a absorção e a assimilação de N (Paul \& Pellny, 2003), o desenvolvimento das plantas e o rendimento de grãos.

Os resultados, nos dois anos, evidenciaram que a presença de alta quantidade de MS (acima de 3,0 tha $\mathrm{t}^{-1}$ ) e a época de dessecação do azevém como cobertura de inverno não prejudicaram o estabelecimento e desenvolvimento inicial de plantas de arroz irrigado,

Quadro 4. Número de panículas de arroz irrigado por $\mathrm{m}^{2}$ em razão da época de dessecação de azevém e da dose de $\mathbf{N}$ aplicada na semeadura do arroz em sucessão

\begin{tabular}{|c|c|c|c|c|c|c|}
\hline \multirow{2}{*}{ Época de dessecação } & \multicolumn{4}{|c|}{ Dose de $N$ na semeadura $\left(\mathrm{kg} \mathrm{ha}^{-1}\right)$} & \multirow{2}{*}{ Média } & \multirow{2}{*}{$\mathbf{C V}^{(1)}$} \\
\hline & $\mathbf{0}$ & 10 & 20 & 40 & & \\
\hline $\mathrm{DAS}^{(2)}$ & \multicolumn{4}{|c|}{ Número de panículas $/ \mathrm{m}^{2}$} & & $\%$ \\
\hline \multicolumn{7}{|c|}{ Ano agrícola 2008/09 } \\
\hline 90 & 332 & 363 & 291 & 292 & $320 \mathrm{~A}$ & \\
\hline 70 & 356 & 305 & 326 & 304 & $323 \mathrm{~A}$ & \\
\hline 50 & 260 & 311 & 325 & 249 & $286 \mathrm{~B}$ & 13,8 \\
\hline 30 & 318 & 324 & 340 & 288 & $318 \mathrm{AB}$ & \\
\hline Média & $317 \mathrm{ab}$ & $326 \mathrm{a}$ & $321 \mathrm{a}$ & $283 \mathrm{~b}$ & & \\
\hline \multicolumn{7}{|c|}{ Ano agrícola 2009/10 } \\
\hline 49 & 490 & 524 & 497 & 611 & $530^{\mathrm{ns}}$ & \\
\hline 34 & 496 & 531 & 500 & 531 & 515 & \\
\hline 19 & 565 & 510 & 493 & 525 & 523 & 12,7 \\
\hline 6 & 457 & 534 & 536 & 520 & 512 & \\
\hline Média & $502^{\mathrm{ns}}$ & 525 & 507 & 547 & & \\
\hline
\end{tabular}

\footnotetext{
$\overline{(1)}$ Coeficiente de variação; ${ }^{(2)}$ Dias antes da semeadura. Médias seguidas pela mesma letra minúscula, na linha, e pela mesma letra
} maiúscula, na coluna, não diferem entre si pelo teste de Duncan; e ${ }^{\text {ns }}$ não significativo $(p<0,05)$. 
Quadro 5. Rendimento de grãos de arroz irrigado em razão de sistemas de manejo de N, na média de quatro épocas de dessecação do azevém, em dois anos agrícolas

\begin{tabular}{|c|c|c|c|c|c|}
\hline \multirow{3}{*}{ Dose total de N } & \multicolumn{3}{|c|}{ Dose e época $^{(1)}$ de aplicação de $N$} & & \\
\hline & \multirow{2}{*}{ Semeadura } & \multicolumn{2}{|c|}{ Cobertura } & \multicolumn{2}{|c|}{ Rendimento de grão } \\
\hline & & $\mathbf{V}_{3-4}$ & $V_{8-9}$ & 2008/09 & $2009 / 10$ \\
\hline \multicolumn{4}{|c|}{$-\mathrm{kg} \mathrm{ha}^{-1}$} & - & \\
\hline 0 & 0 & 0 & 0 & $8,89 \mathrm{~b}$ & $6,29 \mathrm{~b}$ \\
\hline 150 & 0 & 100 & 50 & $10,28 \mathrm{ab}$ & $9,26 \mathrm{a}$ \\
\hline 150 & 10 & 93 & 47 & $10,44 \mathrm{a}$ & $9,03 \mathrm{a}$ \\
\hline 150 & 20 & 86 & 44 & $10,45 \mathrm{a}$ & $9,44 \mathrm{a}$ \\
\hline 150 & 40 & 73 & 37 & $10,55 \mathrm{a}$ & $9,46 \mathrm{a}$ \\
\hline$(\mathrm{CV})^{(2)} \%$ & & & & 15,3 & 9,5 \\
\hline
\end{tabular}

${ }^{(1)}$ De acordo com Counce et al. (2000); ${ }^{(2)}$ coeficiente de variação. Na coluna, médias seguidas pela mesma letra não diferem entre si pelo teste de Duncan $(\mathrm{p}<0,05)$.

bem como não reduziram o rendimento grãos. Além disso, o cultivo contínuo de arroz irrigado sem adubação nitrogenada, durante dois anos, reduziu o potencial de rendimento de grãos. Assim, a aplicação de adequada adubação e a utilização da sucessão azevémarroz irrigado são alternativas viáveis para a atividade orizícola, pois a cobertura de inverno auxilia na ciclagem de nutrientes e no controle de plantas daninhas e doenças, além de melhorar a qualidade de solo (Vernetti Júnior et al., 2009b).

\section{CONCLUSÕES}

1. A presença de palha de azevém, onde as plantas são mantidas de pé, não prejudica o estabelecimento inicial de plantas de arroz cultivado em sucessão.

2. O rendimento de grãos de arroz irrigado cultivado em sucessão ao azevém não é influenciado pela época de dessecação de azevém e pela dose de $\mathrm{N}$ aplicada em semeadura e em cobertura.

3. O cultivo contínuo durante dois anos de arroz irrigado sem adubação nitrogenada reduz o rendimento de grãos. Contudo, a aplicação de adubação nitrogenada no arroz aumenta o rendimento de grãos, desde que haja condições meteorológicas favoráveis para o desenvolvimento das plantas.

\section{LITERATURA CITADA}

ALLISON, F.E. The fate of nitrogen applied to soils. Adv. Agron., 18:219-258, 1966.

AMADO, T.J.C.; MIELNICZUK, J. \& FERNANDES, S.B.V. Leguminosas e adubação mineral como fontes de nitrogênio para o milho em sistemas de preparo de solo. R. Bras. Ci. Solo, 24:179-189, 2000.
CARGNELUTTI FILHO, A.; MATZENAUER, R. \& TRINDADE, J.K. Ajustes de funções de distribuição de probabilidade à radiação solar global no Estado do Rio Grande do Sul. Pesq. Agropec. Bras., 39:1157-1166, 2004.

COMPANHIA NACIONAL DE ABASTECIMENTO CONAB. Disponível em: <http://www.conab.gov.br/ conteudos.php? $\mathrm{a}=1028 \& \mathrm{t}=1>$. Acesso em: 08 nov. 2012.

COUNCE, P.A.; KeISLING,T.C. \& MitChELL, A.J. A uniform, objective, and adaptive system for expressing rice development. Crop Sci., 40:436-443, 2000.

EMPRESA BRASILEIRA DE PESQUISA AGROPECUÁRIA EMBRAPA. Cultivo do arroz irrigado no Brasil. Sistemas de cultivo - Plantio direto e cultivo mínimo em arroz irrigado. 2009. Disponível em: <http:// sistemasde producao.cnptia.embrapa.br/FontesHTML/ Arroz/ArrozIrrigadoBrasil/cap07.htm>. Acesso em: 26 jan. 2012.

INSTITUTO NACIONAL DE METEREOLOGIA - INMET. Disponível em: <http:/www.inmet.gov.br/projetos/rede/ pesquisa/>. Acesso em: 20 nov. 2012.

MARCHESI, D.R.; SILVA, P.R.F.; BOENI, M.; SERPA, M.S.; GROHS, D.S.; MARCHEZAN, E. \& GHELEN, C. Estabelecimento e desenvolvimento inicial de plantas e produtividade de grãos de arroz irrigado em sucessão ao azevém. In: CONGRESSO BRASILEIRO DE ARROZ IRRIGADO, 7., Camboriú, 2011. Anais... Camboriú, Sociedade Sul-Brasileira de Arroz Irrigado, 2011. v.2. p.219-222.

MENEZES, V.G.; ANDREIS, A.; SOUZA, P.R. \& CARRÃO, V.H. Serradela nativa: Uma alternativa de inverno para as várzeas do sul do Brasil. Lav. Arroz., 47:19-22, 1994.

MENEZES, V.G.; MARIOT, C.H.P.; LOPES, M.C.B.; SILVA, P.R.F. \& TEICHMANN, L.L. Semeadura direta de genótipos de arroz irrigado em sucessão a espécies de cobertura de inverno. Pesq. Agropec. Bras., 36:1107-1115, 2001. 
MENEZES, V.G.; ANGHINONI, I.; SILVA, P.R.F.; MACEDO, V.R.M.; GROHS, D.S.; FREITAS, T.F.S.; VALENTE, L.A.L. Projeto 10 - Estratégias de manejo para aumento da produtividade e da sustentabilidade da lavoura de arroz irrigado do RS: Avanços e novos desafios. Cachoeirinha, IRGA/Estação Experimental do Arroz, 2012. 104p.

PAUL, M.J. \& PELLNY, T.K. Carbon metabolite feedback regulation of leaf photosynthesis and development. J. Exper. Bot., 54:539-547, 2003.

SALTON, J. C. Relações entre sistemas de preparo, temperatura e umidade do solo. Porto Alegre, Faculdade de Agronomia, Universidade Federal do Rio Grande do Sul, 1991. 92p. (Dissertação de Mestrado)

SILVA, A.A.; SILVA, P.R.F.; MINETTO, T.; STRIEDER, M.L.; JANDREY, D.B. \& ENDRIG, P.C. Desempenho agronômico e econômico do milho irrigado em sucessão a espécies invernais de cobertura de solo e/ou para produção de grãos. Ci. Rural, 38:620-627, 2008.

SILVA, P.R.F.; ARGENTA, G.; SANGOI, L.; STRIEDER, M.L. \& SILVA, A.A. Estratégias de manejo de coberturas de solo no inverno para cultivo do milho em sucessão no sistema semeadura direta. Ci. Rural, 36:1011-1020, 2006.

SOCIEDADE SUL-BRASILEIRA DE ARROZ IRRIGADO SOSBAI. Arroz irrigado: Recomendações técnicas da pesquisa para o Sul do Brasil. Itajaí, SOSBAI, 2012. 179p.
STRECK, E.V.; KÄMPF, N.; DALMOLIN, R.S.D.; KLAMT, E.; NASCIMENTO, P.C.; SCHNEIDER, P.; GIASSON, E. \& PINTO, L.F.S. Solos do Rio Grande do Sul. Porto Alegre, Emater RS, 2008. 222p.

TEDESCO, M.J.; GIANELLO, C.; BISSANI, C.A.; BOHNEN, H. \& VOLKWEISS, S. J. Análises de solos, plantas e outros materiais. 2. ed. Porto Alegre, Departamento de Solos da Faculdade de Agronomia, UFRGS, 1995. 174p. (Boletim Técnico 5)

VERNETTI JUNIOR, F.J.; GOMES, A.S. \& SCHUCH, L.O.B. Sustentabilidade de sistemas de rotação e sucessão de culturas em solos de várzea no Sul do Brasil. Ci. Rural, 39:1708-1714, 2009a.

VERNETTI JUNIOR, F.J.; GOMES, A.S. \& SCHUCH, L.O.B. Sucessão de culturas em solos de várzea implantadas nos sistemas plantio direto e convencional. R. Bras. Agroci., 15:37-42, 2009b.

VICTORIA, R.L.; PICCOLO, M.C. \& VARGAS, A.A.T. O ciclo do nitrogênio. In: PICCOLO, M.C.; VARGAS, A.A.T.; CARDOSO, E.J.B.N.; TSAI, S.M. \& NEVES, M.C.P., eds. Microbiologia do solo. Viçosa, MG, Sociedade Brasileira de Ciência do Solo, 1992. p.105-120.

VIEIRA, V.M.; SERPA, M.S.; GROHS, D.; GEHLEN, C.; SOARES, B.G. \& MENEZES, G.B. Manejo da adubação nitrogenada no arroz irrigado em sucessão ao azevém. In: CONGRESSO BRASILEIRO DE ARROZ IRRIGADO, 7., Camboriú, 2011. Anais... Camboriú, Sociedade SulBrasileira de Arroz Irrigado, 2011. v.2. p.235-238. 